
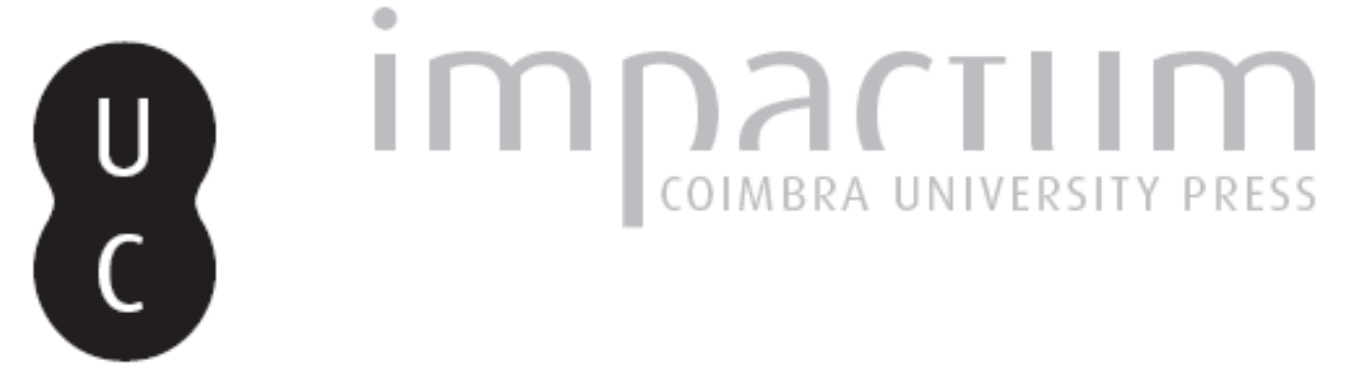

\title{
Movimentos sociais, a construção de sujeitos de direitos e a busca por democratização do Estado
}

\author{
Autor(es): $\quad$ Miranda, Ana Paula Mendes
}

Publicado por: Universidade Católica de Petrópolis

URL

persistente:

URI:http://hdl.handle.net/10316.2/33908

DOI:

DOI:http://dx.doi.org/10.14195/2175-0947_1-1_8

Accessed : $\quad$ 26-Apr-2023 15:19:39

A navegação consulta e descarregamento dos títulos inseridos nas Bibliotecas Digitais UC Digitalis, UC Pombalina e UC Impactum, pressupõem a aceitação plena e sem reservas dos Termos e Condições de Uso destas Bibliotecas Digitais, disponíveis em https://digitalis.uc.pt/pt-pt/termos.

Conforme exposto nos referidos Termos e Condições de Uso, o descarregamento de títulos de acesso restrito requer uma licença válida de autorização devendo o utilizador aceder ao(s) documento(s) a partir de um endereço de IP da instituição detentora da supramencionada licença.

Ao utilizador é apenas permitido o descarregamento para uso pessoal, pelo que o emprego do(s) título(s) descarregado(s) para outro fim, designadamente comercial, carece de autorização do respetivo autor ou editor da obra.

Na medida em que todas as obras da UC Digitalis se encontram protegidas pelo Código do Direito de Autor e Direitos Conexos e demais legislação aplicável, toda a cópia, parcial ou total, deste documento, nos casos em que é legalmente admitida, deverá conter ou fazer-se acompanhar por este aviso.





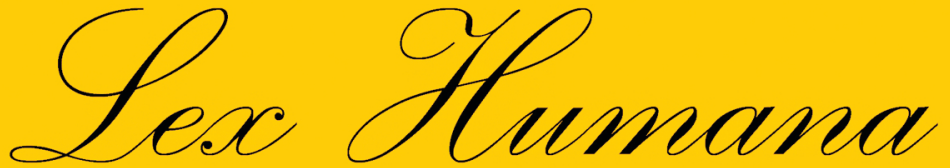

Revista do Programa de Pós-Graduação em Direito da UCP

ISSN(e) 2175-0947

Universidade Católica de Petrópolis Rua Benjamin Constant, 213 - Petrópolis - Centro CEP 25610-130

Tel: (24) 2244-4000 E-mail: lexhumana@ucp.br 


\section{MOVIMENTOS SOCIAIS, A CONSTRUÇÃO DE SUJEITOS DE DIREITOS E A BUSCA POR DEMOCRATIZAÇÃO DO ESTADO}

\section{Ana Paula Mendes de Miranda}

\section{Os movimentos sociais, conflitos e cidadania}

Uma sociedade pode ser vista sob dois aspectos aparentemente opostos - os fatores de manutenção da ordem social, relacionados às tradições, e suas forças de transformação, relacionadas à mudança social. Georges Balandier (1976) afirmava que existem setores da sociedade que em matéria de mudança, intensidade e rapidez podem ser dividos em lentos (religião; arranjos culturais, que definem a nação ou uma etnia, dando-lhe o modo de ser e a sua personalidade) e os que são rápidos (o saber científico e a tecnologia, a economia, as técnicas de governo, de administração dos homens e das coisas). Esta idéia pode parecer contraditória, já que no Brasil, tudo que se refere à governos e adminstrações parecem não mudar. No entanto, é preciso lembrar a tradição não é incompatível com a mudança, do mesmo modo que a mudança não o é com uma continuidade.

O presente artigo pretende levantar algumas questões sobre o que significa a organização da sociedade em movimentos sociais na perspectiva da busca por direitos e sua relação com a democratização estatal. Tal abordagem é necessária, porque embora se fale muito a respeito da democratização, muitas vezes é deixado de lado a discussão sobre como os indivíduos se organizam e se mobilizam na busca por direitos.

Em primeiro lugar, é preciso esclarecer que os movimentos sociais são ações sociais de caráter sócio-político e cultural, que revelam formas distintas dos indivíduos e grupos se organizar e expressar suas demandas. $\mathrm{Na}$ prática, observam-se diferentes estratégias que variam da denúncia, passando pela pressão direta (assembléias, concentrações, passeatas, etc.) até às pressões indiretas (lobby, promoção de ações judiciais). Na atualidade, os principais movimentos sociais atuam por meio de redes ${ }^{1}$ sociais, que podem 1

Redes são estruturas da sociedade contemporânea globalizada e informatizada. Referem-se a um tipo de relação social, que

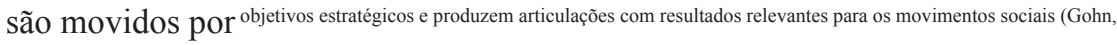


ser locais, regionais, nacionais e internacionais, sendo comum a utilização dos meios de comunicação.

Os movimentos sociais estabelecem processos sociais que criam identidades, transformando-se em fontes de criatividade e inovações socioculturais, conformando o que Alain Touraine chamava de o pulsar da sociedade. Assim, indivíduos que antes estavam dispersos e desorganizados ao se integrarem a grupos para manifestar seus pleitos, passam a compartilhar o sentimento de pertencimento social. Todavia, há que se salientar que alguns movimentos sociais se organizam em torno de idéias conservadoras, baseados em xenofobias, que não buscam mudanças sociais emancipatórias.

As análises sobre a mudança social desenvolvidas por alguns pensadores do séc. XIX, tais como Comte, Spencer e Marx², estavam marcadas por uma visão linear e teleológica. A tradição marxista considerava que os movimentos sociais eram meras expressões de condições estruturais de classe e suas contradições, que seriam suprimidas com o fim da sociedade capitalista. Porém, deve-se salientar que as teorias marxistas não buscavam apenas a explicação dos fenômenos, mas também serviam para orientar a ação dos próprios movimentos sociais. Desta forma, é um erro considerar que o paradigma marxista seja um mero sinônimo de análise do movimento operário, já que a classe operária representava a subjetividade coletiva, com autoconsciência, que seria capaz de se opor ao Estado liberal, mesmo que isso significasse a homogeneização dos sujeitos individuais.

Diferencia-se dessa interpretação, Georg Simmel (1983), que deu um sentido sociológico ao conflito, identificando sua função social. Deste modo, o conflito é pensado como um processo fundamental para a mudança de uma forma de organização à outra, como necessário à vida do grupo, pois age como um elemento que possibilita sua coesão, já que suscita a busca pelo consenso. Para Simmel, o conflito não era patológico ou nocivo à vida

2003).

2 Para Marx, os movimentos sociais, expressos na luta dos trabalhadores e demais oprimidos pela lógica do capital, entram freqüentemente em conflito com a soci $\mathrm{e}^{\text {dade dominante constitui }}$ ndo novas relações sociais e econômicas. A análise dos movimentos sociais sob o prisma do marxismo refere-se a processos de lutas sociais voltadas para a transformação das condições existentes na realidade social, de carências econômicas e/ou opressão sociopolítica e cultural. Esta abordagem $n^{\text {ão diz respeito ao estudo das }}$ revoluções em si, também tratado por Marx e alguns marxistas, mas do processo de luta histórica das classes e camadas sociais em situação

de subordinação. Já $a^{\mathrm{s}}$ revoluções são pontos deste processo, que correspondem a ruptura da "ordem" dominante, quebra da hegemonia do poder das elites e confrontação das forças sociopolíticas em luta, ofensivas ou defensivas. Ver O 18 Brumário e o Manifesto do Partido Comunista. 
social. Suas idéias tiveram grande influência na constituição dos estudos da Escola Sociológica de $\mathrm{Chicago}^{3}$, cuja ênfase nos temas da mudança social, do desenvolvimento da comunidade e pelos processos de participação e educação "para o povo", foram de grande importância para análises posteriores sobre os movimentos sociais.

Uma das mais importantes contribuições de Simmel foi a idéia de que a identidade dos indivíduos é constituída por uma multiplicidade de vínculos sociais, podendo se constituir até mesmo pela resistência aos mesmos. Nesse sentido, Simmel defende que a liberdade não é algo absoluto, mas uma "permuta de contingências" (Souza e Öelze, 2005:11), uma fórmula para lidar com constrangimentos e obrigações, de modo que a idéia de liberdade está associada a uma forma de dependência dos indivíduos em relação aos outros $^{4}$.

As análises desenvolvidas sobre as rupturas e revoltas dos séculos XVIII e XIX apresentaram diversas interpretações para como se constituiu a cidadania no Ocidente. De um lado, Marx considerava que a cidadania era uma forma de alienação burguesa, ao centrar-se nas suas formas legais e políticas de participação, o que ocultaria verdadeiras formas de exclusão. Por outro lado, Tocqueville considerava que o surgimento do cidadão era uma conseqüência da "compulsão" pela igualdade manifesta pela sociedade, como um fenômeno universal, duradouro e não controlável pelo poder humano. Já Weber concebia o desenvolvimento da cidadania como um resultado de processos históricos que afirmaram a autonomia das cidades medievais e a modificação dos meios de fazer a guerra.

Uma nova era para o conceito de cidadania e conquista de direitos foi demonstrado por Thomas H. Marshall (1967). Sua análise foi diretamente influenciada pela realidade do pós-guerra na Inglaterra, e revelava a crença no modelo do Estado de Bem-Estar social. Sua abordagem rompeu com a noção clássica de cidadania política, que dava destaque ao voto como elemento fundamental da participação dos indivíduos nos processos de poder.

Para Marshall, a cidadania está vinculada ao estabelecimento de direitos, em especial, aos direitos civis, que representavam a sua base formal. Os direitos civis correspondem aos direitos fundamentais à vida, à liberdade,

3 Baseou-se em estudos comparativos das instituições e estudos psicossociais, voltados para análises das atitudes humanas (Valladadres \& Kant de Lima, 2000).

4 Esta representação não pode ser associada ao modo pelo qual se entende a noção de liberdade como ausência de limites, comum na sociedade brasileira. 
à propriedade, à igualdade perante a lei. Seus desdobramentos se manifestam nas garantias de ir e vir, de manifestar o pensamento, de se organizar, da inviolabilidade do lar e das correspondências, de não ser preso a não ser pela autoridade competente e de acordo com as leis, e de não ser condenado sem processo legal regular. A sua essência é a liberdade individual.

Os direitos políticos se referem à participação do indivíduo no governo da sociedade. Seu exercício é limitado a partes da população que são capazes de fazer demonstrações políticas, de organizar partidos, de votar e ser votado.

Segundo este modelo é possível haver direitos civis sem direitos políticos, mas os direitos políticos para ter sentido necessitam dos direitos civis, ou seja, para que o voto não seja mera formalidade, é necessária a liberdade de opinião e organização. O seu fundamento é a idéia de autogoverno.

Assim, os direitos civis garantem a vida em sociedade, os direitos políticos asseguram a participação no governo da sociedade, restando aos direitos sociais a função de garantir a participação na riqueza coletiva. A garantia dos direitos à educação, saúde, aposentadoria, trabalho e remuneração justa depende da existência de uma eficiente máquina administrativa. Quando isso não ocorre, pode até haver alguns direitos sociais, mas não se pode alcançar o objetivo da redução de desigualdades e garantia do bemestar. A base dos direitos sociais é a idéia de justiça social.

Ao analisar o estabelecimento do estado de bem-estar social, Marshall expressava uma visão evolutiva e cumulativa de que o capitalismo seria transformado pela distribuição de direitos sociais. Porém, reconhece que a existência do estado de bem-estar social daria substância a noção de direitos, garantindo aos indivíduos a condição de ser sujeito de direitos.

Marshall não se preocupou com a questão da consciência dos cidadãos sobre seus direitos, tampouco valorizou a questão da educação popular como um pré-requisito para a expansão dos direitos.

O modelo de análise desenvolvido por Marshall sobre a construção da cidadania na Inglaterra corresponde a um esquema cronológico e a uma seqüência lógica, onde primeiro surgiram os direitos civis (séc. XVII), depois os direitos políticos (séc. XIX), e por fim, os direitos sociais (séc. $\mathrm{XX)}$. Porém, esse ideal da cidadania plena não se configurou da mesma forma nas sociedades.

Se Marx via a cidadania como uma forma de alienação burguesa, Marshall considerava o desenvolvimento da cidadania uma seqüência 
evolutiva entre tipos de direitos, que era conseqüência da fragmentação institucional característica da modernidade. Assim, Marshall preocupou-se em analisar as instituições que garantiriam o acesso à cidadania, dividindoas em três dimensões: as instituições civis, representadas pelo tribunal; as instituições políticas, representadas pelo parlamento e pelos partidos políticos; e as instituições sociais, que deveriam garantir a universalidade ao cidadão como sujeito de direitos.

Mais recentemente, uma discussão crítica sobre a noção de cidadania realizada por Evelina Dagnino (2004) ressaltou a relação do conceito com uma concepção de justiça redistributiva ${ }^{5}$, e o fato de que a cidadania traz implícita a idéia de um processo civilizatório. Para superar este problema, a autora defende a necessidade de que sejam qualificadas contextualmente o que significa as noções de direitos, a relação público/privado, a representação e de sociedade civil. Assim, a contextualização da cidadania enfatiza sua dimensão histórica e cultural, definida por conflitos reais.

\section{Da adesão irracional à transformação das relações de poder}

Até o início do século XX, o conceito de movimentos sociais contemplava apenas a organização e a ação dos trabalhadores em sindicatos. Ao longo do século XX diversas teorias foram desenvolvidas, das quais salientamos as abordagens da sociologia americana e a teoria dos novos movimentos sociais.

A abordagem da sociologia norte-americana sobre os movimentos sociais está diretamente associada ao próprio desenvolvimento inicial da sociologia naquele país, com recortes distintos, mas tendo como eixo articulador a teoria da ação social e a busca da compreensão do comportamento coletivo.

Os autores analisavam os movimentos em termos de ciclos evolutivos em que seu surgimento, crescimento e propagação ocorriam por intermédio de um processo de comunicação que abrangia contatos, rumores, reações circulares, difusão das idéias etc. As insatisfações que geravam as reivindicações eram vistas como respostas às rápidas mudanças sociais

5 Juhn Rawls (1981) iniciou um debate contemporâneo sobre filosofia política ao propor sua teoria de justiça, que delineou um arcabouço teórico ao Estado de Bem-estar Social, reintroduzindo a discussão sobre eqüidade e justiça social, debatendo em que medida o estado deve interferir na sociedade ára corrigir desigualdades sociais consideradas injustas. 
e à desorganização social subseqüente. A adesão aos movimentos seriam respostas cegas e irracionais de indivíduos desorientados pelo processo de mudança que a sociedade industrial gerava. Nessas abordagens dava-se, portanto, grande importância à reação psicológica pelos indivíduos diante das mudanças, reação considerada como comportamento não-racional ou irracional.

Assim, os comportamentos coletivos eram considerados pela abordagem tradicional norte-americana como fruto de tensões sociais. A idéia da anomia social estava sempre muito presente, assim como explicações centradas nas reações psicológicas às frustrações e aos medos, e nos mecanismos de quebra da ordem social vigente. Estes elementos, aliados às ideologias homogeneizadoras, eram precondições importantes para a emergência dos movimentos sociais.

A progressiva delimitação dos movimentos sociais como campo de estudo pela Sociologia contemporânea (Lallement, 2004; Lechte, 2003), principalmente a partir da década de 60, contribuiu para aprimorar os conceitos analíticos que, embora ainda permanecessem imprecisos, assumiram uma consistência teórica que se pode delimitar em diferentes abordagens, das quais se destacam:

1) A Teoria da Mobilização de Recursos que rejeitou o paradigma tradicional centrado nas condições de privação material e cultural dos indivíduos como a motivação para participação em movimentos sociais, propondo que as ações coletivas deveriam ser entendidas mediante explicações comportamentalistas organizacionais. Esta visão predominou nos Estados Unidos, na década de 60, e definia os movimentos sociais como grupos de interesses. O seu enfoque exclusivamente econômico provou diversas críticas à abordagem voluntarista e individualista.

2) A Teoria da Mobilização Política que se constituiu nos Estados Unidos, nos anos 70, em oposição à Teoria da Mobilização de Recursos, e procurou destacar o desenvolvimento do processo político, da cultura e a interpretação das ações coletivas foi enfocada como processo. Esta abordagem reintroduziu a psicologia social como instrumento de compreensão dos comportamentos coletivos, seu enfoque se aproximou das teorias européias denominadas Novos Movimentos Sociais.

A importância de seu estudo nos dias atuais tem dois motivos: como memória histórica das primeiras teorias dos movimentos 
sociais e ações coletivas; e como busca das referências e matrizes teóricas de vários conceitos que foram retomados nos anos 90 pelo próprio paradigma norte-americano.

Na Europa, depois de 1960, a abordagem marxista, que priorizava a análise pela categoria de luta de classes, passou a ser criticada pelos acionalistas, representados principalmente por pensadores como Alain Touraine ${ }^{6}$, e pelos neomarxistas, tendo como um dos principais representantes, Manuel Castells.

A corrente dos Novos Movimentos Sociais se destacou principalmente com a obra de Alain Touraine (1973), para quem os movimentos sociais seriam o próprio objeto da Sociologia. O sociólogo francês foi profundamente afetado pelos eventos de maio de 1968, e considerava que a ação política estudantil não era apenas reativa, mas possuía uma postura transformadora. A partir das análises sobre o movimento estudantil e de trabalhadores, Touraine desenvolve a idéia de que a ação contra o sistema social é o conceito-chave dos movimentos sociais, visando demonstrar que tal ênfase não leva ao voluntarismo ou ao individualismo. Sua visão foi considerada uma critica à teoria de Parsons sobre o sistema social que, embora explicasse a ação social como uma construção intencional, via as mudanças provocadas pela ação social como disfuncionais. Do mesmo modo, buscou diferenciar-se de uma visão do determinismo econômico marxista.

Nos anos 70, Touraine ainda considerava que a sociologia era o estudo da sociedade, mas diferentemente de Durkheim, acreditava que a sociedade seria um sistema capaz de se transformar. Posteriormente, questionou essa idéia e defendeu que a sociologia deveria tornar-se o estudo da mudança, levando em consideração o fato de que uma ação só assume seu verdadeiro significado em relação à estrutura.

Touraine analisou as mudanças sociais a partir da caracterização de três formas de conflito social:

- um comportamento coletivo defensivo e reativo, em que uma reforma específica pode ser exigida, por exemplo, quando uma ação coletiva é voltada para exigir que diferenças salariais entre pessoas com qualificações iguais sejam abolidas; 
- as lutas sociais cujo objetivo é modificar decisões, nesse caso, os trabalhadores estariam buscando um papel maior na tomada de decisões;

- os movimentos sociais que constituem uma força ativa, voltados para a transformação das relações sociais de poder, seja na fábrica, seja na sociedade.

Para ele, a sociedade não poderia ser reduzida a um sistema de regras e seu funcionamento, sendo necessário, portanto, compreender como os atores são influenciados por intenções, orientações culturais e relações sociais. Nesse sentido, Touraine buscou compreender como os movimentos sociais se constituem em lutas pelo controle da "historicidade", ou seja, a luta contra as estruturas e as formas culturais da vida social, visando à transformação do sistema de ação.

Um exemplo seria o movimento feminista que não reage apenas às diferenças existentes, mas busca uma mudança de normas e valores da vida cultural e social, e cuja luta transcende a política partidária.

Touraine acreditava também que a emergência dos movimentos sociais coincidia com a transformação de sociedades hierárquicas e altamente estratificadas, o que não significa que o princípio da igualdade tenha se implantado totalmente, mas que a industrialização e o crescimento da classe média no Ocidente estariam alterando a estrutura social.

As análises desenvolvidas por diversos pensadores que são incluídos no grupo dos Novos Movimentos Sociais possuem em comum a crítica à abordagem clássica marxista e um intenso debate com as teorias norte-americanas contemporâneas da ação coletiva. Apesar disso, há uma grande divergência entre os trabalhos. Merece destaque o fato de que essas abordagens (re) valorizaram temas geralmente minimizados pelas esquerdas tradicionais, como os movimentos por direitos civis, significando uma reconfiguração da idéia de democracia como um espaço de criação para novos direitos.

Enquanto Touraine realiza uma análise macrossocietal, a abordagem do italiano Alberto Melucci (apud Gohn, 2004) 
se volta à análise de estruturas micro, tendo um enfoque mais psicossocial, combinando a análise da subjetividade à análise das condições político-ideológicas. O ponto de partida de sua obra é a teoria da ação coletiva, entendida como a união de vários tipos de conflitos baseados no comportamento dos atores num sistema social.

Melucci considera que o movimento social é uma construção analítica e não um objeto empírico ou um fenômeno observável, e que a mera existência de um conflito não é suficiente para qualificar uma ação como movimento social. Para o autor, o conflito não é algo imanente à natureza humana, só podendo ser considerado em face das relações sociais. Destaca ainda o caráter relacional, ou seja, de criação de identidade coletiva dos atores em relação ao movimento.

Um outro enfoque dado aos movimentos sociais tem sido chamado de neomarxista ou pós-marxista, que se caracteriza por uma releitura do marxismo ortodoxo, feita por historiadores, tais como Eric Hobsbawn, Edward P. Thompson e George Rudé, que enfatizam a necessidade de compreensão da vida social e cultural, em detrimento do eixo econômico. Para Hobsbawn, o que produziria a consciência dos trabalhadores seria o estilo de vida no meio urbano. Sua contribuição à análise dos movimentos sociais está na distinção entre os que possuem uma dimensão reformista, cujo foco é o aperfeiçoamento da estrutura social, e os revolucionários, cujo foco está na transformação da estrutura.

Uma outra abordagem neomarxista segue a teoria crítica iniciada pela Escola de Frankfurt. Claus Offe (apud Gohn, 2004) priorizava a análise das articulações entre o campo político e o sociocultural, ou seja, o autor busca combinar as perspectivas macro e micro na análise dos movimentos sociais. Contesta a tese da irracionalidade dos movimentos sociais, sustentando que os mesmos são um modo de atuar politicamente racional em resposta a um conjunto específico de problemas. Os movimentos sociais seriam a base de constituição de uma nova ordem, cujos atores intervêm na esfera pública e na esfera privada, mas ressalta a dificuldade de continuidade dos movimentos. 
As diferentes abordagens conceituais trouxeram críticas aos modelos vigentes de regulação social, voltando o foco à identificação de outras formas de opressão que não estavam restritas as relações de produção capitalista, destacando os temas relacionados ao reconhecimento de direitos, tais como, o meio ambiente, o combate às discriminações de gênero e de raça. Outro paradigma que foi estabelecido, contemporaneamente, diz respeito ao enfoque dado à qualidade de vida. Nesse sentido, as reivindicações dos movimentos sociais não podem visar somente as necessidades básicas, mas a transformação social emancipatória, que permita alterar as relações de poder desigual em relações de autoridade partilhada.

Nesta ótica, os direitos não correspondem às garantias inscritas nas leis e nas instituições, e sim ao modo pelo quais as relações sociais se estruturam ${ }^{7}$. O abandono da perspectiva formal do direito não representa a negação de seu papel de garantidor da cidadania e da democracia. O que se pretende é reforçar o papel dos movimentos sociais na construção de espaços de ampliação e democratização estatal.

3. A construção de sujeitos de direitos e a busca por democratização do Estado

O associativismo predominante dos anos 90 não deriva de mobilização de massas, tradicionalmente composta a partir de núcleos de militantes que se dedicam a uma causa, mas sim de processos de mobilizações pontuais, realizados a partir do atendimento a um apelo feito por alguma entidade, fundamentada em objetivos humanitários.

O novo associativismo, também chamado de participação cidadã, é mais propositivo e menos reivindicativo, sendo baseado numa concepção ampla de cidadania, que não se restringe ao direito ao voto, mas constrói o direito da vida do ser humano como um todo. Baseia-se numa concepção de cultura cidadã, fundada em valores éticos universais e

$7 \quad$ No caso brasileiro, as relações sociais expressam uma grande confusão entre direitos e privilégios. Ver Kant de Lima (2004).. 
impessoais e também, numa concepção democrática radical que visa fortalecer a sociedade civil para a construção de uma realidade social sem exclusões de qualquer natureza. Envolve também direitos e deveres do cidadão (diferentemente da concepção neoliberal de cidadania que exclui os direitos), onde os deveres se articulam à idéia de civilidade.

Nos anos 90, observou-se também a construção de novos conceitos, tais como, cidadania planetária, sustentabilidade democrática, etc., que preconizavam o respeito às diferenças culturais e foram gerados dentro de outros movimentos sociais, como a "Ética na Política" 8 .

$\mathrm{O}$ desenvolvimento que o conceito movimentos sociais teve nos últimos anos não produziu um consenso sobre seu significado entre os pesquisadores, o que sinaliza para a necessidade de uma maior discussão acerca da validade conceitual do termo, mesmo porque ele vem sendo utilizado indiscriminadamente para classificar qualquer tipo de associação civil.

Para Maria da Glória Gohn (2004), é necessário discutir o itinerário histórico-conceitual dos diferentes paradigmas, que devido a suas peculiaridades influenciam as análises sobre os movimentos sociais. A autora analisa as características dos movimentos sociais latino-americanos ${ }^{9}$ e destaca que, embora tenha havido uma mobilização massiva, há pouca produção acadêmica sobre o tema. Salienta que este cenário tem se alterado no Brasil, no México, na Argentina e no Chile, que têm desenvolvido um número crescente de

8 A Ética na Política foi um importante movimento ocorrido nos anos 90, no Brasil, e que chegou a depor um Presidente da República por suspeita de envolvimento em atos de corrupção.

9 No Brasil, o final da década de 70 e parte dos anos 80 foram marcados por movimentos sociais contra o regime militar, dos quais destaco os comitês de anistia, as entidades de familiares dos desaparecidos na ditadura, as Comissões de Justiça e Paz, a Ordem dos Advogados do Brasil e a Associação Brasileira de Imprensa. A partir de 1990, começaram a surgir outras formas de organização popular mais institucionalizadas, como Fóruns de luta pela moradia, pela reforma urbana. Outros movimentos que surgiram foram os de mulheres, homossexuais, afro-brasileiros, jovens, indígenas, funcionários públicos e ecologistas. 
pesquisas sobre o comportamento destes movimentos ${ }^{10}$.

Para a autora, o debate foi marcado nas décadas de 60 e 70 por estudos que compreendiam a América Latina como uma realidade dual, dividida em uma face moderna e outra atrasada, cuja ótica era o estudo das elites e dos processos de desenvolvimento. Por outro lado, havia uma visão antiestado nos movimentos sociais, devido às lutas contra o regime militar.

É na década de 80 , que começa a se intensificar a produção acadêmica sobre os movimentos sociais no Brasil, que coincide com o que Ruth Cardoso (2004) chama de período da institucionalização dos movimentos. O contexto político da "redemocratização" possibilitou o estabelecimento de novas formas de relação entre os movimentos, as agências públicas e os partidos políticos.

Um outro fator importante para a compreensão dos movimentos sociais no Brasil estava relacionado com a influência da Teologia da Libertação, que mobilizou e engajou camadas pobres da população na luta por justiça social.

Há que se considerarque os movimentos sociais podem trabalhar para a construção de uma agenda emancipatória e transformadora, que estimule o desenvolvimento de práticas democráticas, que possibilitam a construção de uma nova noção de cidadania, ou seja, cidadania como estratégia política.

É com esta perspectiva que José Murilo de Carvalho (2003) analisa o Movimento dos Sem-Terra (MST) como um avanço que resultou da redemocratização do país, pois representou a incorporação à vida política de uma parcela da população tradicionalmente excluída pela força do latifúndio. Embora reconheça que os métodos utilizados, invasão de terras públicas ou não cultivadas, podem tangenciar a ilegalidade, José Murilo de Carvalho acha que os mesmos devem ser considerados legítimos em função da lentidão histórica dos governos em resolver o problema agrário no país. O pensador aponta ainda o surgimento de organizações não-governamentais como um processo de democratização das relações entre sociedade e Estado, porque provocaram a ampliação da participação social no diagnóstico, encaminhamento e solução de problemas sociais. Neste processo é possível 10 Ver também Alvarez et al (2000). 
se observar o desenvolvimento de estratégias de "empoderamento" que levam os atores da sociedade civil organizada a se perceberem como sujeitos sociais, ou seja, é na busca por mecanismos que possibilitem que a cidadania se enraíze nas práticas sociais.

Portanto, é pela mobilização da sociedade civil organizada que se poderá pensar numa conquista de direitos, e não de privilégios, o que representará a ressignificação das relações público-privado, que levarão à superação do padrão oligárquico, autoritário e patrimonialista, que têm marcado a cultura brasileira. A existência dos movimentos sociais não conservadores pode favorecer a emergência de uma idéia de cidadania como um direito a ter direitos, que se conquista de baixo para cima e transforma as relações sociais, estabelecendo um padrão de sociabilidade que rompe com o autoritarismo.

O desafio não é pequeno, tendo em vista que no caso brasileiro há diversos obstáculos a serem superados, dos quais destaco:

- $\quad$ a superaração da perspectiva de que direitos sejam apenas garantias inscritas na lei e nas instituições;

a reestruturação do Estado brasileiro, com a transformação de sua tradição de patrimonialismo e clientelismo;

- $\quad$ a revisão do papel do cidadão, que cada vez mais se torna um mero consumidor, afastado de preocupações políticas e dos problemas coletivos;

a inadequação dos órgãos encarregados da segurança pública e da justiça para o cumprimento de sua função;

o fim da divisão em classes no que se refere a garantia dos direitos civis: os de primeira classe (doutores); os de segunda classe (os cidadãos simples) - que estão sujeitos aos rigores e aos benefícios da lei; e os de terceira classe (os “elementos"), ou ignoram seus direitos ou os têm sistematicamente desrespeitados por outros cidadãos, pelos governos e pela polícia.

Há que se considerar que se não há a garantia da igualdade jurídica dos cidadãos (Kant de Lima et al, 2005), não há como se pensar em direitos civis no Brasil, e enquanto vigorar a idéia de que há uns que são mais iguais que outros, não será possível se pensar na construção democrática de uma ordem pública no Brasil, que seja fundada na representação plural dos interesses.

Um outro processo pode ser relacionado a diversas experiências de aprofundamento e inovação democrática, de 
ampliação do campo da política e construção da cidadania que vem se desenvolvendo mais recentemente. Para Olvera (2006), este campo de experiências tem possibilitado a renovação do debate sobre a democracia, que se divide em dois discursos parecidos do ponto de vista teórico, mas que são distintos no campo da prática.

O primeiro seria os projetos democráticos participativos, que funcionam como forma de assegurar a governabilidade.

O segundo se refere ao projeto neoliberal de privatização de amplas áreas, tradicionalmente vinculadas a políticas públicas, que vem acompanhado por um discurso participacionista e de revalorização simbólica da sociedade civil, entendida como o terceiro setor $^{11}$. Muitas vezes incorporam o discurso técnico-gerencial e suas estratégias de despolitização. Uma visão homogênea e amorfa do terceiro setor contribui para difundir a idéia dicotômica de que este se constitui num pólo de virtude, em oposição ao Estado, como um inimigo a ser enfrentado.

Evelina Dagnino (2002) tem demonstrado em suas pesquisas que a sociedade civil está formada por uma diversidade de atores, o que inclui os conservadores, com formatos distintos (sindicatos, associações, redes, etc.), e uma pluralidade de práticas e projetos políticos, com várias formas de relação com o Estado.

Nesse sentido, é preciso pensar as demandas por direitos num cenário complexo, como a América Latina e o Brasil, onde as diferentes tradições políticas têm gerado modos peculiares de combinar elementos participativos e autoritários. Assim, é possível compreender como as políticas populistas foram capazes de impulsionar grandes mobilizações populares, abrir espaço para as classes trabalhadoras e implantar alguns direitos sociais, ao mesmo tempo em que proporcionava a subordinação da classe trabalhadora, de modo clientelista, às elites políticas.

Olvera destaca também o modo pelo qual uma parte da esquerda, com múltiplas correntes e expressões, contribuiu para criar uma cultura política autoritária, em função da idéia leninista da centralidade dos partidos como instâncias dirigentes das organizações sociais, bem como a transformação de algumas pautas reivindicatórias em assuntos sem importância, em especial, a demanda por direitos civis de grupos minoritários. 
Fenômeno inverso é observado na Igreja Católica, que teve grande influência entre os movimentos sociais com a Teologia da Libertação, em especial no Brasil, Peru, El Salvador, Guatemala e Nicarágua, fundando as bases de um projeto democrático de mobilização, principalmente, em áreas rurais. Atualmente, observase a emergência de correntes fundamentalistas e conservadoras.

Trata-se, então, de pensar que o fenômeno associativo é multidimensional, o que obriga a privilegiar sua dimensão microssocial para observar como são construídas as formas de intervenção capazes de desenvolver dimensões cívicas e democráticas, colocando em cheque posturas clientelistas ou corporativas.

$\mathrm{O}$ desafio que se coloca para os movimentos sociais no séc. XXI (Gohn, 2003; Leher \& Setúbal, 2005; Santos, 2006) é o de ampliar as redes que possibilitarão uma nova estratégia de articulação dos atores, visando a luta pela defesa das culturas locais em oposição às conseqüências da globalização, a luta pela ética na política, a valorização da esfera pública como o espaço da institucionalidade das ações coletivas. No Brasil, observase a organização dos movimentos sociais, no início do século XXI, em torno dos seguintes eixos principais:

na cidade;

Lutas e conquistas por condições de habitabilidade

Mobilização e organização popular em torno de estruturas institucionais de participação na estrutura políticoadministrativa da cidade;

Mobilização de movimentos de recuperação de estruturas ambientais e físico-espaciais;

- Movimentos contra o desemprego;

- Movimentos de solidariedade e apoio a programas com meninos de rua, portadores de HIV e deficiências físicas;

- $\quad$ MST e suas vias de articulações com as cidades;

- Movimentos étnico-raciais;

- Movimentos de mulheres e homossexuais;

- Movimentos rurais péla terra, reforma agrária;

globalização.

Contra políticas neoliberais e os efeitos da

O movimento antiglobalização nega a forma como a ordem capitalista instituída vigente se reproduz e não a ordem em si. É 
movido pela busca de soluções alternativas aos problemas sociais e à própria preservação da vida no planeta. Suas ações são motivadas pela solidariedade e não pelo ódio.

Um dos principais pontos do movimento antiglobalização é a crítica que ele faz à cultura do lucro, considera-se que esse tipo de cultura deve ser substituído pela cultura do ser humano pleno, com direito à vida e uma sociedade ética com respeito aos direitos humanos fundamentais.

Diferentemente das lutas sociais da década de 80, o movimento antiglobalização une as causas daquelas lutas às causas objetivas dadas pela estrutura econômica e imposições do mercado numa economia globalizada. Com isso, os conflitos ganham caráter universal e o movimento social retoma as antigas polaridades: dominantes $\mathrm{X}$ dominados, ricos $\mathrm{X}$ pobres e etc.

Os movimentos antiglobalização trouxeram uma série de novidades que contribuíram muito para os movimentos sociais do novo milênio. Suas ações deveriam servir como exemplo aos movimentos que anseiam por uma sociedade sem desigualdades com justiça social.

O ideal básico parece ser a criação de um sujeito social, que redefine o espaço da cidadania, portador de um sentimento de uma tripla exclusão relativa - econômica, política e cultural -, mais do que o desejo de participar das decisões. As reivindicações, portanto, são assumidas como direito, tomados como auto-evidentes. Derivam daí formas de desobediência civil para enfrentar decisões autoritárias do Estado, na tentativa de deslegitimá-lo.

No plano estatal, observa-se um processo de ampliação e tentativa de democratização da gestão por meio de instâncias, tais como fóruns, conselhos, câmaras setoriais, voltados para a inclusão da participação popular, visando uma maior transparência e publicidade de políticas públicas.

Boaventura de Sousa Santos (2006) chama de "Estadonovíssimo-movimento-social", a concepção de reforma do Estado que propõe uma articulação privilegiada entre os princípios de Estado e da comunidade, voltadas para atender a quatro bens públicos (a legitimidade, o bem-estar social e econômico, a segurança, a identidade social) ${ }^{12}$ visando a democratização interna dos agentes Boaventura S. Santos ressalta que o Relatório sobre o Desenvolvimento 
estatais e não estatais. Seu objetivo é lançar os fundamentos de uma nova cultura política, que permita pensar e desejar a transformação social e emancipatória, ou seja, o conjunto de processos econômicos, sociais, políticos e culturais para transformar as relações de poder desigual em relações de autoridade partilhada. Deste modo, a luta pelo princípio da igualdade seja conduzida de par com a luta pelo reconhecimento do princípio da diferença, transformando as práticas institucionais.

Em termos da tradição política brasileira, os conselhos de políticas públicas são arranjos institucionais inéditos, uma conquista da sociedade civil para imprimir níveis crescentes de democratização às políticas públicas e ao Estado, que em nosso país têm forte trajetória de centralização e concentração de poder. Os conselhos, nos moldes definidos pela Constituição Federal de 1988, são espaços públicos com força legal para atuar nas políticas públicas, na definição de suas prioridades, de seus conteúdos e recursos orçamentários, de segmentos sociais a serem atendidos e na avaliação dos resultados ${ }^{13}$.

A composição plural e heterogênea, com representação da sociedade civil e do governo em diferentes formatos, caracteriza os conselhos como instâncias de negociação de conflitos entre diferentes grupos e interesses, portanto, como campo de disputas políticas, de conceitos e processos, de significados e resultantes políticos. Os conselhos são canais importantes de participação coletiva, que possibilitam a criação de uma nova cultura política e novas relações políticas entre governos e cidadãos.

Muitos desses desafios atuais estão relacionados ao contexto adverso em que diversos conselhos foram implantados no Brasil - de esvaziamento das responsabilidades públicas do Estado, de desqualificação das instâncias de representação coletivas, de fragmentação do espaço público e de despolitização da política -

de 1997 do Banco Mundial marcou uma mudança de paradigma do que se considera a reforma do Estado, rompendo a visão de que o potencial de fracasso e de dano do Estado só pode ser reduzido com a diminuição do tamanho e do âmbito do Estado, reconhecendo ainda que o capitalismo global não pode dispensar a existência de um Estado Forte.

13 Cabe ressaltar que a existência de Conselhos Comunitários de Segurança nos estados e do Conselho Nacional de Justiça ainda não foi analisado de forma a compreender suas dinâmicas de funcionamento. 
processos que fragilizam a capacidade de a sociedade civil exercer pressão direta sobre os rumos da ação estatal. Outras dificuldades decorrem da própria lógica de estruturação das políticas públicas na sociedade e da natureza da intervenção estatal nesse campo.

Desse modo, a transformação dos movimentos sociais por meio de novas práticas políticas, engendradas por outras transformações de ordem econômica, política e social, coloca uma questão: diante desses processos recentes, a ação coletiva não se organiza em torno de dois pólos identificados e visíveis, mas difusos, fragmentados, cuja diversidade não é apreensível em apenas um conceito como o de movimentos sociais.

A complexidade e diversidade destas instituições levantam a necessidade de compreensão de como, na prática, estes espaços se constituem em lócus de debates que permitem um efetivo exercício de cidadania e a construção de sujeitos de direitos.

\section{Referências Bibliográficas}

ALVAREZ, Sonia E., DAGNINO, Evelina \& ESCOBAR, Arturo. Cultura e política nos movimentos sociais latino-americanos. Belo Horizonte: UFMG, 2000.

BALANDIER, George. As dinâmicas sociais: sentido e poder. São Paulo: Difel, 1976.

CARDOSO, Ruth. A trajetória dos movimentos sociais. In: DAGNINO, Evelina (org). Anos 90: política e sociedade no Brasil. 4 ed. São Paulo: Brasiliense, 2004.

CARVALHO, José Murilo de. Cidadania no Brasil: o longo caminho. Rio de Janeiro: Civilização Brasileira, 2003.

DAGNINO, Evelina (org). Anos 90: política e sociedade no Brasil. 4 ed. São Paulo: Brasiliense, 2004.

DAGNINO, Evelina (org). Sociedade Civil e Espaços Públicos no Brasil. São Paulo: Paz e Terra, 2002. 
GADEA, Carlos \& SCHERER-WARREN, Ilse. A contribuição de Alain Touraine para o debate sobre sujeito e democracia latinoamericanos. Revista Sociologia e Política, Curitiba, 25, p.39-45, nov. 2005.

GOHN, Maria da Glória. Teorias dos movimentos sociais: paradigmas clássicos e contemporâneos. São Paulo: Loyola, 2004.

GOHN, Maria da Glória. (org). Movimentos Sociais no Início do Século XXI. Petrópolis: Vozes, 2003.

KANT DE LIMA, Roberto; AMORIM, Maria Stella de; MENDES, Regina Lúcia Teixeira (Org.). Ensaios sobre a Igualdade Jurídica. Acesso à Justiça Criminal e Direitos de Cidadania no Brasil. Rio de Janeiro: Lumen Juris, 2005.

KANT DE LIMA, Roberto. Direitos Civis e Direitos Humanos: uma tradição judiciária pré-republicana? São Paulo em Perspectiva, São Paulo, SP, v. 18, p. 49-59, 2004.

LALLEMENT, Michel. História das idéias sociológicas: de Parsons aos contemporâneos. Petrópolis: Vozes, 2004.

LECHTE, John. Cinqüenta pensadores contemporâneos essenciais: do estruturalismo à pós-modernidade. Rio de Janeiro: DIFEL, 2003.

LEHRER, Roberto \& SETÚBAL, Mariana (org). Pensamento crítico e movimentos sociais: diálogos para uma nova práxis. São Paulo: Cortez, 2005.

MARSHALL, T. H. Cidadania, Classe Social e Status. Rio de Janeiro: Zahar, 1967.

MARX, Karl. Manifesto do Partido Comunista. São Paulo: Global, 1987.

MARX, Karl. O 18 Brumário e Cartas a Kulgemann. Rio de Janeiro: Paz e Terra, 1974. 
OLVERA, Alberto J. La heterogeneidad de la sociedad civil y del Estado en America Latina y sus efectos sobre la innovación democrática. III Congreso de la Asociación Latinoamericana de Ciencia Política, Campinas / SP, 4-6 setembro 2006.

RAWLS, John. Uma teoria de justiça. Brasília: UNB, 1981.

SANTOS, Boaventura de Sousa. A gramática do tempo: para uma nova cultura política. São Paulo: Cortez, 2006.

SIMMEL, George. George Simmel: sociologia. São Paulo: Ática, 1983.

SOUZA, Jessé \& ÖELZE, Berthold. Simmel e a modernidade. Brasília: UNB, 2005.

TOURAINE, Alain. Production de la société. Paris: Seuil, 1973.

VALLADARES, Licia P. \& KANT DE LIMA, Roberto. A Escola de Chicago: entrevista com Isaac Joseph, BIB - Revista Brasileira de Informação Bibliográfica em Ciências Sociais, Rio de Janeiro, 49: 3-13, 2000. 